\title{
$\underline{\text { Souls and the Location of Time in Physics IV 14, 223 }} \underline{\text { a6-223 }} \underline{\text { a9 }}$ Tim Loughlin
}

It is also worth investigating how time is related to the soul, and for what reason it is that time is thought to be in everything - on earth and in the sea and in the heavens. Is it that it is a property or a state of change, being the number [of it], and all these things are changeable, since they are all in place, and time and change are together both in potentiality and in actual operation? One might find it a difficult question, whether if there were no soul there would be time or not. For if it is impossible that there should be something to do the counting, it is also impossible that anything should be countable, so that it is clear that there would be no number either, for number is either that which has been counted or that which can be. But if there is nothing that has it in its nature to count except soul, and of soul [the part which is] intellect, then it is impossible that there should be time if there is no soul, except that there could be that $\mathrm{X}$ which time is, whatever $\mathrm{X}$ makes it what it is; as for example if it is possible for there to be change without soul. The before and after are in change, and time is these qua countable. $\left(223^{\mathrm{a}} 16-29\right)^{1}$

\subsection{Introduction}

In the above passage Aristotle is concerned with what seem to be two separate questions:

(Q1) How is time related to the soul?

(Q2) For what reason is it that time is thought to be in everything?

Interpretations of this passage have focused on $(\mathrm{Q} 1)$, which is fitting since this is the question to which Aristotle seems to devote more attention. There are, however, two reasons to pay some attention to (Q2). First, although we often speak of things being located in time, ${ }^{2}$ there is little discussion of the location of time. It's worthwhile considering just what might be meant by time being in something and why it might be thought that time is located in everything. Second, the way that Aristotle introduces $(\mathrm{Q} 2)$ indicates that it may have some relation to $(\mathrm{Q} 1)$. Notice that Aristotle raises some further questions concerning (Q2), but rather than answering these

$1 \quad$ I will be using Edward Hussey's (1993) translation, except where noted otherwise. All alterations in typeface are inserted by me for emphasis. Parenthetical remarks are present in the source text, bracketed remarks are inserted by the translator, and braced remarks are inserted by me.

2 I will address the issue of being in time at some length in section 2.22 below. 
questions, he turns his attention to (Q1). Is something he says about (Q1) supposed to answer the questions connected to (Q2)? Do the questions connected to (Q2) somehow raise (Q1) or does (Q1) somehow raise (Q2)? Or, if there is no relation between the two at all, why does Aristotle raise the questions together in this way? In this paper I explore why it is that Aristotle juxtaposes (Q1) and (Q2) in the way he does and what the location of time has to do with it.

I argue that Aristotle is committed to the claim that time only exists where change is countable and that this explains the juxtaposition of (Q1) and (Q2). Why might Aristotle believe that there is time only where there is countable change? Why might he believe that change is located anywhere at all? He maintains that time is the before and after of change qua counted or countable. If time is identical to change qua countable and changes have locations, then time will be located where and only where countable changes are located. If Aristotle's theory commits him to there being time only where change is countable, and if there are or might be uncountable changes, then the belief that time is in everything seems to challenge Aristotle's theory, since he seems to be committed to the claim that time is not in everything. If this is the position that Aristotle finds himself in, he can argue either that his theory is not committed to the problematic claim, that no change is uncountable, or that the belief that time is in everything is false. However, his theory is pretty clearly committed to the problematic claim and he explicitly endorses the existence of uncountable changes, specifically in the heavens. So, he must take the belief that time is in everything to be false. However, given Aristotle's somewhat deferential attitude toward folk beliefs, if he were to choose the third option, he might feel the need to find some truth in the claim that time is everywhere. Even if he were dismissive of folk beliefs, it would still be incumbent on him to explain why this false belief is so widely held. One way to do this would be to explain that, although time might not be located in something, the substratum 
of time might still be. In such a situation, it makes sense to speak of time as being in something that it, strictly speaking, is not. Thus, in answering (Q1), Aristotle defends his theory of time from the challenge implicit in (Q2).

\subsection{Time is Located Only Where Countable Change Is}

In this section I argue that Aristotle is committed to the claim that time is located only where countable change is located. My argument for this claim rests on Aristotle's definition of time as 'a number of change in respect of the before and after, $\left(219^{b} 1\right)^{\prime}$ and further claims he makes about the number of change.

\subsection{Evidence in Favor}

Just what Aristotle means by 'the number of change in respect to the before and after' is a controversial topic. ${ }^{3}$ Thankfully, I need not enter into that controversy in order to establish that Aristotle took time to be located only where countable change is located. The important issue for my purposes in the above definition is the relation between change and the number of change. If the number of change is something that is located only where countable change is located, then this will be enough to establish my first claim, regardless of the exact meaning of Aristotle's definition.

Even narrowing the scope of my investigation in this way still seems to leave me with a difficult interpretative issue, i.e. Aristotle's metaphysics of abstract numbers. For example, some might think that if Aristotle takes abstract numbers to be located nowhere that would be the end

3 See Julia Annas (1976), David Bostock (1980/2006), Sarah Waterlow (1982), Edward Hussey (1983), Richard Sorabji (1983), Mario Mignucci (1984), Ursula Coope (2005), Anthony Roark (2003, 2004, 2005, 2009), and Stephen Makin (2007). 
for my thesis. This would indeed be problematic if Aristotle is referring to abstract numbers in his definition of time, but he isn't. Aristotle makes it clear in several passages that the 'number of change' in the definition of time does not refer to the kind of number that we count with, i.e., the abstract numbers, but instead the kind of number that we count. For example:

But number is [so called] in two ways: we call number both (a) that which is counted and countable, and (b) that by which we count. Time is that which is counted and not that by which we count. (That by which we count is different from that which is counted.) $\left(219^{\mathrm{b}} 6-8\right)$

And again:

It is the same time, too, everywhere together, but before and after it is not the same [time], since the present alteration is one, but the past alteration and the future one are different, and time is not the number by which we count but the number which is counted, and this number turns out to be always different before and after, because the nows are different. (The number of a hundred horses and that of a hundred men is one and the same, but the things of which it is the number are different - the horses are different from the men.) $\left(220^{\mathrm{b}} 5-13\right)$

These passages don't just show that Aristotle isn't thinking about abstract numbers, they also make it prima facie plausible that Aristotle is committed to the claim that the number of change is located only where change is located. After all, when we count horses the things we count are, obviously, the horses and, trivially, the horses are located only where the horses are located. But the strongest evidence that the number of change is located only where change is located is the passage in which Aristotle defines time:

But time, too, we become acquainted with when we mark off change, marking it off by the before and after, and we say that time has passed when we get a perception of the before and after in change. We mark off change by taking them to be different things, and some other thing between them; for whenever we conceive of the limits as other than the middle, and the soul says that the nows are two, one before and one after, then it is and this it is that we say time is. (What is marked off by the now is thought to be time: let this be taken as true.) (219 $22-30)$

Consider the claims that Aristotle makes in this passage: (i) the before and after are two nows 
('the soul says that the nows are two, one before and one after'), ${ }^{4}$ (ii) we mark off change by the before and after ('we mark off change, marking it off by the before and after,' and 'We mark off change by taking them \{i.e., the before and after\} to be different things'), and (iii) what is marked off by the now is time ('What is marked off by the now is thought to be time: let this be taken as true'). It follows from (i) and (ii) that change is what is marked off by the now, and from this and (iii) it follows that time is change, or at least some aspect of change. If time is change or some aspect of change, then time can only be where change is.

Furthermore, Aristotle is committed not to the claim that time is located wherever there is any change, but rather to the claim that time is located only where there is countable change. Recall from above $\left(219^{\mathrm{b}} 6-8\right)$ that he identifies time with the number of change, where number is that which is counted or countable. ${ }^{5}$ Consider also that he presents his definition of time at $219^{\mathrm{b}} 1$, after he claims that 'what is marked off by the now is thought to be time, (219'29-30)' a thought he urges us to take as true. This indicates that the marked off aspect of change is identical to the number of change, and so only changes that are countable can be marked off. ${ }^{6}$ So, there is strong textual evidence supporting the claim that Aristotle is committed to time being located only where countable change is located.

\subsection{Evidence Against}

$4 \quad$ This claim is bolstered further by Aristotle's later claims: "It is the now that measures time, considered as before and after," $\left(219^{\mathrm{b}} 11\right)$ and "the now is the before and after, considered as countable." $\left(21^{9} \mathrm{~b} 27\right)$

5 It is worth pointing out that Aristotle repeats the claim that number is that which is counted or countable in the passage I began this paper with $\left(223^{\mathrm{a}} 16-223^{\mathrm{a}} 29\right)$.

6 This also supports the stronger claim that only and all changes that are countable can be marked off, but the left to right reading is not necessary to establish my thesis. 
There are three sets of passages that raise problems for this interpretation. The first set $\left(221^{\mathrm{a}} 16-18,221^{\mathrm{a}} 26-30,221^{\mathrm{b}} 4-6\right.$, and $\left.221^{\mathrm{b}} 28-31\right)$ indicates that objects that are in time are surrounded by time. The worry is that if objects that are in time are surrounded by time, then it would seem that time cannot be located only where there is countable change. The second set of passages $\left(221^{\mathrm{b}} 28-31\right.$ and $\left.222^{\mathrm{b}} 30-223^{\mathrm{a}} 15\right)$ indicates that everything that comes to be, ceases to be, or changes is in time. The worry is that if all changing objects are in time, then it would seem that there is time wherever there is change, even if that change is uncountable. The third problem is raised by just one passage, $220^{\mathrm{b}} 5$, which indicates that there is only one time. The worry is that if there is only one time, but there are multiple numbers of change (each countable change having its own number), then Aristotle cannot mean for us to strictly identify time with the number of change.

2.21 First Problem. First, I will address the worry that if objects that are in time are surrounded by time, then it would seem that time cannot be located only where there is countable change. Consider a quantity of water increasing in temperature from 75 degrees to 80 degrees. The change is countable and so the water is in time. But Aristotle claims:

... objects are [in time] as they are in number. If so, they are surrounded by time just as the things in number are by number and the things in place by place. $\left(221^{\mathrm{a}} 16-18\right)$

And again:

Since what is in time is so as in a number, there will be found a time greater than anything that is in time, so that of necessity all things that are in time are surrounded by time, just like all other things that are in something: e.g., the things that are in place [are surrounded] by place. $\left(221^{\mathrm{a}} 26-30\right)^{7}$

Thus, the quantity of water is surrounded by time. Insofar as it makes sense to speak of the

$7 \quad$ The other two passages, $221^{\mathrm{b}} 4-6$, and $221^{\mathrm{b}} 28-31$, raise identical worries. 
location of place, objects in place are surrounded by place and so place is located not just where objects in place are located but also in the immediate vicinity of objects in place. If we understand objects in time in the same way we understand objects in place, then there would be time literally located around objects in time. It is implausible to think that all countable changes are surrounded only by countable changes, and so it must be that some time is located where there is no countable change. This contradicts my claim that Aristotle takes time to be located only where countable change is located.

However, it is implausible to think that Aristotle is here suggesting that time is literally located around objects in time. He explicitly says that objects are in time as they are in number, not as they are in place, and that things that are in number are surrounded by number. Numbers are not literally located around objects in number. Consider a hundred horses and a hundred men. The horses and the men are both in number, i.e. they are both a hundred in number. When Aristotle says that objects in number are surrounded by number, he means that there is a number before (less than) and after (greater than) ${ }^{8}$ the number of those objects. Likewise, we should understand Aristotle as asserting in the above passages that when objects are in time there is a time before and after the time they are in. This could be so even if there is no time located in the immediate vicinity of the objects.

2.22 Second Problem. More problematic is the worry that if all changing objects are

\footnotetext{
$8 \quad$ Actually, if there is a smallest number, which Aristotle asserts that there is $\left(220^{\mathrm{a}} 27-30\right)$, then not all objects in number are not completely surrounded by number, since there will be some objects in number of which there is no lesser number. Still, there would be a greater number and so they would be surrounded in the sense that there is always a number greater than anything in number. This point is consistent with Aristotle's claim above that "what is in time is so as in a number, there will be found a time greater than anything that is in time."
} 
in time, then it seems that there is time wherever there is change, even if that change is uncountable. Aristotle asserts:

Now all things that admit of ceasing-to-be and coming-to-be and generally, that at some time are and at some time are not, must be in time - there will be some greater time which will exceed both their being and that [time] which measures their being. $\left(221^{\mathrm{b}} 28-31\right)$

And again:

Now that we have determined these matters in this way, it is manifest that every alteration and all that changes is in time. 'Faster' and 'slower' apply to every alteration, since in every case this is obviously true ... But the before is in time, for we use 'before' and 'after' according to the distance from the now, and the now is the boundary of the past and the future. So, since the nows are in time, the before and after will also be in time ... So, since the before is in time, and the before accompanies every change, it is manifest that every alteration and every change is in time. $\left(222^{\mathrm{b}} 30-223^{\mathrm{a}} 15\right)$

If some changes are uncountable, and all changes are in time, then some uncountable changes are in time. If changes are in time only if time is located where they are, then it follows that time is located wherever there is change and not just where there is countable change.

As a first response, I might deny that Aristotle takes changes to be in time only if time is located where they are. There is some support for this in Aristotle's explanation of how it is that different changes can be in the same time. Since time is the number of change for Aristotle, and different changes with qualitatively identical numbers, i.e., that have the same measure, will have quantitatively different numbers, it seems that Aristotle is committed to there being as many times as there are countable changes. But it is highly intuitive that time is the same everywhere. So, Aristotle must provide an account of how this is so. To accomplish this, he suggests that, although it is not the case that there is only one time everywhere, still we can speak truly when we say that two changes occur in the same time because we merely assert that the numbers of the two changes are of the same kind, i.e. the same measure (2242-15). This establishes that Aristotle is comfortable with reinterpreting common speech about time so that it conforms to his 
theory.

Furthermore, Aristotle indicates that it is appropriate to measure one change by the units of another change, as when we say that a journey takes a day $\left(223^{\mathrm{b}} 12-23\right)$. In this case, a day is a unit of the change of the heavens, and yet we use it to measure the change in location of a traveler. Given this, it seems that Aristotle takes it to be appropriate to measure one change by the time of another change. But then a change need not be measured by its own time in order to be in time, and so there need not be time located where a change is in order for that change to be in time. This taken with the argument from the previous paragraph might indicate that, although it is strictly false to assert that the time of an uncountable change is, say, two days, still we can speak truly when we say 'The time of an uncountable change is two days' by using this sentence to assert only that the number of change of the heavens as marked from the beginning to the end of the uncountable change is two (days). If this is so, then when Aristotle says that all changes are in time, he need not be asserting that time is located wherever change is located.

Unfortunately, this response is unavailable. Aristotle's explicit account of what it is to be in time is as follows:

Since time is a measure of change and of being-in-change, and since it measures change by defining some change which will measure out the whole change (just as the cubit measures length by defining some magnitude which will measure off the whole magnitude), and since for a change the being in time is the being measured by time both of the change itself and of its being (time measures at once the change and the being of the change, and this is what it is, for the change, to be in time, viz. its being's being measured), it is clear, then, that for other things too this is what it is to be in time: their being's being measured by time. For to be in time is one or other of two things: either, to be when time is, or [to be in it] in the way in which we say that some things are 'in number', which means that [something is in number] either as a part or property of number, and, in general, that it is some aspect of number, or that there is a number of it. And since time is a number, the now and the before and everything of that kind are in time in the way in which the limit and the odd and the even are in number (they are aspects of number as the others are of time). But objects are [in time] as they are in number. If so, they are surrounded by time just as things in number are by number and the things in place by place. $\left(220^{\mathrm{b}} 32-221^{\mathrm{a}} 18\right)$ 
Aristotle here asserts that objects, and presumably changes as well, are in time as they are in number. Changes are not in number in the way that even and odd are in number, i.e., by being aspects of number, but rather in number in the way that one hundred horses are one hundred in number, i.e., there is a number of them. So, for a change to be in time is for there to be a number of that change. But the time of a change just is the number of the change, and so any change that is in time is, ipso facto, where time is. We must, then, take Aristotle's comments concerning measuring one change by the time of another change to only apply to changes that are countable. ${ }^{9}$ So, the response above cannot work.

However, while this passage rules out one response it shows the way to another. Because Aristotle explicitly asserts here that the only changes that are in time are changes that are countable it cannot be that he takes all change to be in time. Why, then, does Aristotle say that all changes are in time at $222^{\mathrm{b}} 30-223^{\mathrm{a}} 15$ ? One possibility is that he is speaking loosely. According to Aristotle, the heavens are in perpetual circular motion, and so they change eternally. If we take $222^{\mathrm{b}} 30-223^{\mathrm{a}} 15$ at face value, then, the heavens are in time. But elsewhere Aristotle asserts:

So it is manifest that the things that always are, considered as such, are not in time, for they are not surrounded by time, nor is their being measured by time, and an indication of this is that they are not acted on at all by time either, which shows that they are not in time. $\left(221^{\mathrm{b}} 4-6\right)$

9 There is a puzzle here. Aristotle explicitly denies that the motion of the heavens is in time since there is no time greater than the time of the motion of the heavens. If the motion of the heavens is not in time, then it cannot be countable both because being a countable change is just what it is to be a change in time and because a change is only countable it is in number and it is only in number there is a number greater than it, which is not the case for motion of the heavens. Given this, how can the number of the motion of the heavens be used to measure other changes? As with all of Aristotle's discussions of the heavens, this is a difficult issue and I will not address it here. 
So it cannot be that Aristotle means to assert that all changes are in time. This is what we should expect given the passage at $221^{\mathrm{b}} 28-31$, in which Aristotle insists only that all changes that are surrounded by time are in time. If he later claims that all changes are in time, we should understand the previous qualification to be implicit unless there is some indication that Aristotle means to be negating that qualification, which there isn't.

Still, we might ask why Aristotle asserts that all changes that are surrounded by time are in time. Might there not be some uncountable changes that are surrounded by time? Given what Aristotle has said, the answer is 'no'. Changes are in time in the way that changes are in number. If changes are in number, then there is a number of the change. So, if changes are in time, then there is a time of the change, i.e., the change is countable. If a change is surrounded by time, then the change is in time. So, if a change is surrounded by time, then it is countable. Therefore, there are no changes surrounded by time that are uncountable. Notice that this is not the same as asserting that there are no uncountable changes. Aristotle believes that such changes do exist, e.g., the change of the heavens. He just denies that they are in time. When Aristotle asserts that all non-eternal changes are in time, then, he does so either because he means countable non-eternal changes or because he thinks there are no uncountable non-eternal changes. Either way, he is not committed to there being time where there is no countable change.

2.23 Third Problem. If Aristotle identifies time with change qua countable, then since there are multiple distinct countable changes he must take there to be multiple distinct times. So, if Aristotle thinks that there is only one time everywhere, then Aristotle cannot mean for time to be identical to change qua countable. But Aristotle does assert that, ' $\{i\} t$ is the same time, too, everywhere together, $\left(220^{b} 5\right)^{\prime}$ so it seems that he cannot mean to strictly identify time with 
change qua countable.

It is true that Aristotle's assertion at $220^{\mathrm{b}} 5$ is, if taken as a literal expression of Aristotle's position, incompatible with the claim that time is strictly identical to change qua countable. However, there is evidence to suggest that Aristotle is speaking loosely at $220^{\mathrm{b}} 5$, but no evidence to suggest that he is doing so at 21922-30. Recall that Aristotle takes it that different changes being in the same time is analogous to different groups of objects being in the same number. Since the number in question is the number we count, not the number we count with, this sameness in number cannot mean that the numbers of, say, a group of seven horses and a group of seven dogs is truly identical. Rather, they are merely the same in kind (224a2-15). Likewise, we can assert that two changes are in the same time without being committed to denying that there are two distinct times. So, Aristotle's assertion at $220^{\mathrm{b}} 5$ does not really conflict with his definition of time at change qua countable.

\subsection{Why is Time Thought to be Everywhere?}

In the previous section I argued that Aristotle is committed to the claim that time is located only where countable change is located. In this section I first argue that this supports a plausible account of why Aristotle juxtaposes (Q1) and (Q2) at 223 $16-29$. I then contrast my interpretation of this passage with other recent interpretations.

\subsection{The Interpretation}

In this paper I set out to provide an account of the relation between (Q1) and (Q2). (Q1) asks about the relation between time and the soul, while (Q2) asks why it is thought that time is in everything. I want to suggest that $(\mathrm{Q} 1)$ is related to $(\mathrm{Q} 2)$ insofar as Aristotle's answer to (Q1) 
draws attention to a way to answer (Q2) that is not at odds with Aristotle's theory of time.

(Q2) is a dangerous question for Aristotle because if time is thought to be in everything because time really is in everything, including everything in the heavens, then time is in the changes of the heavenly bodies. In order for a change to have a number it must be surrounded by number, i.e., there must be a number greater than it. But since the motion of the heavenly bodies is eternal there can be no number greater than it. So the motion of the heavenly bodies is not in number. But according to Aristotle, time just is the number of change. So if time is thought to be in everything because time really is in everything, then Aristotle's definition of time cannot be correct. It is therefore incumbent on Aristotle to provide an account of why it is thought that time is in everything when, strictly speaking, this is not so.

One way to provide such an account is to consider a case in which time clearly does not exist, and yet there is a reason to think that it does exist. To this end Aristotle considers what would be the case if no intellective souls existed. Since only intellective souls have the ability to count, nothing would be countable if intellective souls did not exist. ${ }^{10}$ Since time just is change qua countable, if countable change were impossible then time would be impossible. This is all pretty straightforward. However, Aristotle adds a caveat. He asserts:

...it is impossible that there should be time if there is no soul, except that there could be that $\mathrm{X}$ which time is, whatever $\mathrm{X}$ makes it what it is; as for example if it is possible for there to be change without soul. The before and after are in change, and time is these qua countable. $\left(223^{\mathrm{a}} 26-29\right)$

10 There is some difficulty in the text here. Aristotle actually asserts that if it is impossible that any intellective souls exist, then it is impossible that anything is countable. He then goes on to conclude that if no intellective souls exist (notice the dropped 'impossible'), then time would be impossible. Mario Mignucci (1984) makes much of this disparity in his interpretation of this passage. I will address this in section 3.23 below. As I will make clear, it is an advantage of my interpretation that it makes explicable Aristotle's apparent carelessness. 
Changes are not dependent on the existence of the soul and so they would still exist even without souls. Furthermore, the before and after in change would also still exist, and time just is the before and after in change, albeit qua countable. So, the thing that is actually time would still exist without souls. It just would not be time in such a case. Consider a mother. A mother just is a woman who bears a certain relation to her children. In a world where this woman did not have any children she would still exist but she would no longer be a mother. Still, we might truly say, 'This mother would exist even if she hadn't had any children', because the woman that is actually the mother would exist. Likewise, even though time would not exist if there were no souls, still we might truly think, 'Time would exist even if there were no souls', because the thing that actually is time would exist, i.e., the before and after in change. This account of the relation between souls and time gives us a reason to think that even without souls time would exist, even though, strictly speaking, time would not exist without souls.

I think that this is an intuitively plausible reading of Aristotle's answer to (Q1). It is further bolstered by his claim that 'One might find it a difficult question, whether if there were no soul there would be time or not.' Without his caveat playing an important role in his answer to (Q1) it does not seem like a particularly difficult question. The answer, that time would not exist without souls, follows pretty immediately from claims that Aristotle makes elsewhere concerning time, number, and the soul. The question is only made difficult because it still seems that time would in some way exist without souls. The difficulty lies in providing an explanation as to why this is so, which Aristotle does in his caveat.

If this is what Aristotle is up to in answering (Q1), it provides him with a safe way of answering (Q2), i.e., of explaining why it is that it is thought that time is everywhere given that time is not, strictly speaking, everywhere. Since time is the before and after in change qua 
countable, and the before and after in change still exist even when change is not countable, the before and after would exist in eternal changes as well. So, the before and after would exist in the motion of the heavens. Since the existence of the before and after in change is what accounts for the truth in claims like, 'Time would exist even if there were no souls', it could also account for the truth in claims like, 'Time is in everything - on earth and in the sea and in the heavens.' The thing that is time is in the heavens on Aristotle's account; it's just not time there. This is a reason to think that time exists everywhere. Thus, it makes sense that Aristotle would raise (Q1) and (Q2) together, since his answer to (Q1) allows him to safely answer (Q2).

This relationship between (Q1) and (Q2) is supported by the further questions Aristotle asks after raising $(\mathrm{Q} 2)$ :

Is it that it \{i.e., time\} is a property or a state of change, being the number [of it], and all these things \{i.e., everything on earth and in the sea and in the heavens \} are changeable, since they are all in place, and time and change are together both in potentiality and in actual operation? $\left(223^{\mathrm{a}} 18-21\right)$

Here he is asking if the reason that it is thought that time is in everything is that everything is changeable and time is necessarily in whatever is changeable. ${ }^{11}$ He raises this question without providing an explicit answer to it. If we take his answer to (Q1) to be unrelated to (Q2), then this is a curious omission. However, on my interpretation of the relation between (Q1) and (Q2), his answer to (Q1) answers the question above. The reason suggested at $223^{\mathrm{a}} 18-21$ cannot be the reason that time is thought to be in everything, since Aristotle goes on to argue that time and change are not together in potentiality. Were there no souls, there would still be change but there would be no time. Instead, the reason for the belief is the one I suggest above. Notice how this interpretation makes sense of the order of the passage. First, Aristotle raises (Q1) and (Q2) as though they are related to one another. Then, he raises the question at $223^{\mathrm{a}} 18-21$. He then

$11 \quad$ See Aristotle's comments about time and objects at rest at $221^{\mathrm{b}} 7-22$. 
answers that question in the negative by providing an answer to (Q1), thus establishing the relation between (Q1) and (Q2). Finally, in qualifying his answer to (Q1) he provides a plausible answer to $(\mathrm{Q} 2)$ that is compatible with his theory of time.

Looking at the passage before $223^{\mathrm{a}} 16-29$ we find more evidence in support of this interpretation. At $223^{\mathrm{a}} 14-15$ Aristotle asserts that, 'since the before is in time, and the before accompanies every change, it is manifest that every alteration and every change is in time.' Immediately after this passage he raises (Q1) and (Q2). My interpretation makes sense of this structure. Having made a universal claim, he considers and responds to objections to that claim: time would not exist if there were no souls and time does not exist in the heavens. His answers to $(\mathrm{Q} 1)$ and $(\mathrm{Q} 2)$ make his claim at $223^{\mathrm{a}} 14-15$ more plausible: every non-eternal change is actually in time, strictly speaking, and all changes are in time, loosely speaking.

One might object that if Aristotle's only goal at $223^{\mathrm{a}} 16-29$ is just to respond to (Q2) in a way that is safe for his theory, there is no real reason for him to address (Q1) at all. Furthermore, if this is his goal, we should expect him to draw explicit conclusions concerning (Q2) in this passage, which he does not do. It seems more likely that his goal in this passage is to address (Q1), not (Q2).

As a first response, I should point out that I have not claimed that Aristotle's only goal is to provide a response to $(\mathrm{Q} 2)$ that is safe for his theory. Rather, I have argued that taking this to be one goal provides a plausible interpretation of this passage. It is very possible, and indeed likely, that Aristotle was interested in drawing out the implications of his theory for the relation between souls and time. I have not tried to explain (Q2) by down-playing (Q1). Rather, my goal was to explain why $(\mathrm{Q} 1)$ and $(\mathrm{Q} 2)$ are juxtaposed as they are. I agree that were (Q1) and (Q2) to be raised in different chapters, then my interpretation of the relationship between the questions 
would be significantly less plausible. Furthermore, I agree that were Aristotle to make it explicit that (Q2) raises problems for his theory and that his answer to (Q1) helps him to deal with those problems, my interpretation would be on much better footing. But the fact is that Aristotle does not explain the relationship between (Q1) and (Q2). This is the puzzle that motivated this paper. So, unless there is strong reason to explain the juxtaposition of (Q1) and (Q2) in a way that is inconsistent with my interpretation, I take it that I can safely dismiss these worries.

\subsection{Other Interpretations}

In the previous section I provided evidence in support of my interpretation of $223^{\mathrm{a}} 16-29$. In this section, I explore other interpretations of this passage. Since no other interpretations are concerned to explain why it is that Aristotle juxtaposes (Q1) and (Q2), no other interpretations present a direct challenge to mine. However, just what Aristotle is doing in his answer to (Q1) is an issue discussed at some length in the literature, and since my thesis depends on the claim that Aristotle here suggests that the thing that time actually is might exist even if time does not exist, I will focus on this aspect of competing interpretations.

3.21 Sorabji. In his exploration of $223^{\mathrm{a}} 16-29$, Sorabji focuses on the issue of countability. In particular, he is concerned to find out just why it is that Aristotle took countability to be dependent on the existence of souls. He considers various reasons for this in light of commentary by later philosophers. However, this issue is not relevant to my interpretation so long as it remains the case that Aristotle suggests that, while nothing would be countable if there were no souls, the before and after in change would still exist. But Sorabji does make trouble for this claim. 
It is strange, Sorabji suggests, that Aristotle would entertain the possibility that there might be the before and after in change without time. How can something change in no time at all? In order to avoid attributing this position to Aristotle, Sorabji argues that Aristotle only considered the possibility of change without soul hypothetically:

The "if" \{in "if it is possible for there to be change without soul"\} is not fulfilled in Aristotle's view. For change in the universe requires motion, which in turn requires an unmoved mover or movers, who must act as final causes, inspiring the souls of the spheres which carry round the stars. (1983: 93)

The argument, then, is that given claims Aristotle makes elsewhere, he is committed to change existing only if souls exist. Therefore, it is not possible for there to be change without soul and we need not take Aristotle to be suggesting that the before and after in change could exist without souls.

There are two available responses to this problem. First, even if Sorabji is correct and Aristotle took it to be impossible that there could be change without soul, this is not really necessary for my interpretation. If Aristotle's answer to (Q1) makes it clear why we might think time exists somewhere when it does not really exist there, it does not really matter whether or not the case that makes this clear is possible. However, it would be strange that Aristotle would choose such a case to illustrate his point. But we need not concede Sorabji's claim to him. It is not obvious that Aristotle means for the existence of change to imply the existence of intellective souls. So, if we read his caveat as being limited to considerations of what would be the case were there no intellective souls, it is not obvious that the 'if' is not fulfilled in Aristotle's view.

3.22 Coope. On the face of it, Aristotle's treatment of (Q1) seems to involve the following two questions:

(Q3) Is a state of affairs in which there is time but no souls possible? 
(Q4) Is a state of affairs in which there is change but no souls possible?

If these are the questions that he is asking, and, furthermore, the answers he gives are 'no' and 'yes' respectively, then it seems that Aristotle is here committed to the claim that a state of affairs in which there is change but no time is possible, e.g., if there were no souls. And this indeed seems to be incompatible with his earlier claim that:

... it is manifest that every alteration and all that changes is in time. "Faster" and "slower" apply to every alteration, since in every case this is obviously true. (I say that changes faster which is earlier to alter into a given [state], changing over the same extension and with uniform change (e.g., in the case of locomotion, if both things are changing along the curve or along the straight line, and in other cases similarly).) But the before is in time, for we use "before" and "after" according to the distance from the now, and the now is the boundary of the past and the future. So, since the nows are in time, the before and after will also be in time; for the distance from the now will be in that in which the now is. ("Before" is applied in opposite ways in relation to the past time and to future time: in the past, we call "before" what is further from the now, and "after" what is nearer to it, but in the future we call "before" what is nearer and "after" what is further.) So, since the before is in time, and the before accompanies every change, it is manifest that every alteration of every change is in time. $\left(222^{\mathrm{b}} 30-223^{\mathrm{a}} 15\right)$

Coope maintains that we should not, however, read Aristotle as asking (Q3) and (Q4). Her primary reason for thinking that he is asking some other questions is the following argument. Aristotle maintains that there always have been and always will be intellective souls. Aristotle maintains further that whatever exists always, i.e., eternally, exists necessarily. So, Aristotle maintains that intellective souls exist necessarily. But if Aristotle maintains this, then the answers to (Q3) and (Q4) should both be 'no,' and trivially so, since it is impossible for there to be no intellective souls. But clearly Aristotle takes himself to be asking interesting and puzzling questions, not trivial questions. So, Coope maintains, we should interpret this passage in some way that has Aristotle asking questions other than those above (2005: 161).

Coope suggests the following questions:

(Q5) Does the nature of time imply that time cannot exist without intellective souls? 
(Q6) Does the nature of change imply that change cannot exist without intellective souls? Since a thing's nature is determined by its definition for Aristotle and since the definition of time is 'a number of change in respect of the before and after', it follows from Aristotle's argument in $223^{\mathrm{a}} 16-29$ that the nature of time implies that time cannot exist without intellective souls. On the other hand, Aristotle asserts that change is 'the actuality of that which potentially is, qua such.' If, for example, a mass of bronze has the potential to be a statue, then the process of that potential being actualized, i.e., the bronze being made into a statue, is change in the bronze. Likewise, if a ball at point $A$ has the potential of being at point $B$, then the process of that potential being actualized, i.e., the ball moving from point $A$ to point $B$, is change in the ball. Coope asserts that the addition of 'qua such' to Aristotle's account is meant to distinguish the actuality of the bronze insofar as it is bronze, which would not be a change in the bronze, ${ }^{12}$ from the actuality of the bronze insofar as it is potentially a statue, which would be a change, and the actuality of the ball insofar as it is at point $A$, which would not be a change, from the actuality of the ball insofar as it is potentially at point $B$, which would be a change. So, since Aristotle defines change in terms of potentiality, and since this potentiality is not necessarily dependent on the existence of souls, Coope maintains that it does not follow from the definition of change alone that it cannot exist without souls.

So, on Coope's interpretation, Aristotle's assertions at $223^{\mathrm{a}} 21-9$ and $222^{\mathrm{b}} 30-223^{\mathrm{a}} 15$ are consistent. At $222^{\mathrm{b}} 30-223^{\mathrm{a}} 15$ Aristotle is asserting that change could not exist without time, and he does assert at $223^{\mathrm{a}} 21-9$, if Coope is correct, that it follows from the definition of time that time could not exist without souls. It follows from this that change could not exist without souls but, Coope argues, Aristotle does not assert that this follows from the definition of change and in

$12 \quad$ Since it was already bronze. 
fact suggests that this does not follow from the definition of change.

This raises problems for my interpretation. If Aristotle is here asserting something about the definition of time and change, and not suggesting that change could exist even if souls did not exist, then his answer to (Q1) would not suggest an answer to (Q2) that is compatible with his theory of time.

However, there is a difficulty with Coope's interpretation. For her interpretation to be plausible, it must be that it follows in some way from the definition of time that time could not exist without souls and that it does not follow in the same way from the definition of change that change could not exist without souls. In what way does it follow from the definition of time that time could not exist without souls? It certainly does not follow directly. Rather, it follows from the definition of time, i.e., a number of change in respect of the before and after, the definition of number, i.e., that which is counted or countable, and auxiliary claims concerning the relation between countability and the soul. Given this, it is not obvious that it does not follow in the same way from the definition of change that change could not exist without souls. After all, given the definition of change, i.e., the actuality of that which potentially is, qua such, auxiliary claims concerning the relation between change and time, particularly those made at $222^{\mathrm{b}} 30-223^{\mathrm{a}} 15$, and definitions and claims considered above concerning time, number, and countability, it does follow that change could not exist without souls. The difference between the way in which it follows from the definition of time that time could not exist without souls and the way in which it follows from the definition of change that change could not exist without souls is one of degree, not of kind. There are simply more steps between the definition of change and the relevant conclusion than there are between the definition of time and the relevant conclusion. It is not clear why this should make it the case that the conclusion concerning the 
relation of soul and time follows from the definition of time but the corresponding conclusion concerning the relation of soul and change does not follow from the definition of change. Thus, Coope's interpretation is incomplete as it stands.

This does, however, leave me with the following challenge: why does Aristotle seem to assert at $223^{\mathrm{a}} 21-29$ that change can exist without time while, at $222^{\mathrm{b}} 30-223^{\mathrm{a}} 15$, he clearly states that this could not be so? It is important to remember that we have to take Aristotle to be implicitly qualifying his claims in $222^{\mathrm{b}} 30-223^{\mathrm{a}} 15$ to refer only to non-eternal changes no matter what interpretation we accept. Given this, it is not implausible to think that Aristotle also implicitly qualifies these claims to refer only to what is actually the case, not to what might be the case were the world otherwise. So, it is not implausible to think that $222^{\mathrm{b}} 30-223^{\mathrm{a}} 15$ and $223^{\text {a2 }} 1-29$ are not incompatible after all.

3.23 Inconsistency in Aristotle's Argument. In closing, I want to consider a complication in Aristotle's argument at $223^{a} 21-29$. At $223^{a} 25$, Aristotle explicitly asserts that, 'if there is nothing that has it in its nature to count except soul ..., then it is impossible that there should be time if there is not soul.' Mario Mignucci (1984) argues that this conclusion is not warranted by Aristotle's argument and, further, that Aristotle did not intend to draw a conclusion this strong. Rather, Mignucci takes Aristotle to be arguing for the weaker conclusion that if it is impossible for there to be souls, then it is impossible for there to be time. Crucially, Aristotle claims that 'if it is impossible for there to be something to do the counting, it is also impossible that anything should be countable.' But from this premise Aristotle cannot validly infer that if there were nothing to do the counting, then there would be nothing countable. Mignucci writes:

What is clear is that Aristotle assumes [if it is impossible for there to be something which does the counting, then it is impossible for there to be something which can be counted], 
but not [if it is not the case that there is something which does the counting, then it is not the case that there is something which can be counted] as a self-evident statement. It is the impossibility of the existence of someone doing the counting that entails the impossibility of there being countable things. But let us imagine that nobody does the counting (without implying that it is impossible for there to be anyone who does the counting). It does not follow from this that countable things cannot exist. There can be ten horses even if nobody actually counts them. The possibility of having ten horses is compromised only by the hypothesis that there cannot be someone doing the counting. (1984: 186)

On the other hand, Sorabji suggests that Aristotle never intended the weaker premises. He writes:

...why, at the beginning, does he envisage that there "cannot" exist someone to do the counting, and that there cannot be anything countable? But I presume he only means it cannot be the case that, if souls does not exist, there exists someone doing the counting. And again, it cannot be the case that, if no one exists to do the counting, there is anything countable. (1983: 90)

This reinterpretation of Aristotle's premises does support the strong conclusion.

So, Mignucci argues that Aristotle meant the weaker premises and the weaker conclusion, while Sorabji argues that Aristotle meant the stronger premises and the stronger conclusion. Coope, on the other hand, argues that, although Aristotle's argument only supports the weaker conclusion, his weaker conclusion, when bolstered by claims he makes elsewhere, implies his stronger conclusion. She writes:

On Aristotle's view, the weaker conclusion [if it is impossible for there to be anything that is able to count, then it is impossible for there to be time] implies the stronger [if there is nothing able to count, then there can be not time]. The ability to count is an ability that a thing has in virtue of having an intellective soul. But to have an intellective soul is to be a member of some kind that, if it exists, exists eternally. Hence, if there were ever a time at which nothing was able to count, then there would never be anything able to count. But according to Aristotle, a world in which there was never anything able to count would be a world in which it was impossible for there to be anything to count. (2005: 165)

How is this argument supposed to work? Take it as established that if it is impossible for there to be anything able to count, then it is impossible for there to be time. Now, that which is able to 
count is able to count in virtue of having an intellective soul. Since humans have intellective souls $^{13}$ and since humans exist eternally, that which is able to count exists eternally if it exists ever. So, if that which is able to count ever fails to exist, then it eternally fails to exist. Coope attributes to Aristotle the claim that whatever eternally fails to exist is impossible. So, if there is nothing able to count, then it is impossible for there to be anything able to count. This conclusion and the weaker conclusion above entail the stronger conclusion that if there is nothing able to count, then it is impossible for there to be time.

There is, however, at least one dubious step in this argument. There are two senses in which whatever has the ability to count has that ability in virtue of having an intellective soul. The first sense just amounts to the claim that only that which has an intellective soul has the ability to count. The second sense amounts to the claim that whatever has an intellective soul has the ability to count. On the second sense, the claim is patently implausible. It seems that a young child has an intellective soul but might not have the ability to count. But on the first sense, the claim does not support Coope's argument. Even granting that intellective souls exist eternally if they exist at all, on the first sense of the claim, it would not follow that whatever is able to count exists eternally if it exists at all. Perhaps due to something in the water, we might all preserve our intellective souls but lose our ability to count. So, in order to make her interpretation plausible, Coope must show that the ability to count is inseparable from having an intellective soul in the second sense above.

At the very least, we can conclude that Aristotle is not as careful in this passage as we would expect him to be if he is trying to establish an important conclusion concerning the relation of soul and time. However, if this is not his primary goal, if, as I have argued, he is

$13 \quad$ See footnote on p.165 of Coope (2005). 
using the case of a world without souls as a way of illustrating an answer to (Q2), then this lapse is understandable. On my interpretation, what matters for Aristotle's purposes in this passage is that he shows why it is that people think that time is everywhere when, strictly speaking, it is not. $^{14}$

University of Nebraska - Lincoln

1010 Oldfather Hall

PO. Box 880321

Lincoln, NE 68588-0321

tloughlin2@unl.edu

\section{Works Cited}

Annas, J. Aristotle's Metaphysics M and N (Oxford: Clarendon Press 1976)

Bostock, D. “Aristotle's Account of Time", in D. Bostock, ed. Space, Time, Matter, and Form (New York: Oxford University Press 1980/2006) 135-57.

Coope, U. Time for Aristotle (New York: Oxford University Press 2005)

Hussey, E. Aristotle's Physics III and IV (Oxford: Clarendon Press 1983)

Makin, S. “About Time for Aristotle", The Philosophical Quarterly 57 (2007) 280-93.

Mignucci, M. “Aristotle's Arithmetic", in A. Graeser, ed. Mathematics and Metaphysics in Aristotle: Akten des X. Symposium Aristotelicum (Bern and Stuttgart: Paul Haupt 1984) $175-212$

14 Thanks to the Graduate Student Colloquium Series at UNL and to Steve Swartzer in particular for helpful feedback. Thanks also to Harry Ide for his patience and invaluable comments. 
Sorabji, R. Time, Creation and the Continuum (Ithaca: Cornell University Press 1983)

Roark, A. “Aristotle's Definition of Time is Not Circular”, Ancient Philosophy 23 (2003) 30118. . "Why Aristotle Says There Is No Time Without Change", Apeiron 37 (2004) 227-47. . “Aristotelian Temporal Passage”, Philosophical Writings 28 (2005) 23-33. . "Book Review: Time for Aristotle, by Ursula Coope", Mind 118 (2009) 459-62

Waterlow, S. Passage and Possibility (Oxford: Oxford University Press 1982) 